\title{
Correction of unilateral posterior cross bite in primary dentition by slow dentoalveolar expansion. - A case report.
}

\author{
Dr. Rashmi G Chour ${ }^{1}$, Dr. Girish V. Chour ${ }^{2}$, Dr. Shilpa Sasalwad ${ }^{3}$, \\ Dr. Sangeetha K.M ${ }^{4}$,Dr. Suryakanth. M. Pai ${ }^{5}$, Dr. Poornima. $\mathrm{P}^{6}$. \\ ${ }^{I}$ Department of Pedodontics \& Preventive dentistry, PMNM Dental College \& Hospital, Bagalkot, Karnataka, \\ India. ${ }^{2}$ Department of Oral \& Maxillofacial Surgery, PMNM Dental College \& Hospital, Bagalkot, Karnataka, \\ India. ${ }^{3,4,5,6}$ Department of Pedodontics \& Preventive dentistry, College of Dental Sciences, Davanagere, \\ Karnataka, India.
}

\begin{abstract}
The incidence of posterior crossbite in the primary dentition has been reported as $8-22 \%$. The crossbite usually results from bilateral maxillary constriction and is commonly associated with an occlusion guided lateral deviation of the mandible upon closing. Correction of the posteriorcross bite in the primary dentition is indicated to establish a stable occlusion and avoid possible deleterious effects on the developing temporomandibular joint and Treatment in the primary dentition results in the eruption of the first permanent molars in normal transverse relationship in $84 \%$ of the cases. The aim of the present case report shows the management of unilateral posteriorcross bite by slow dentoalveolar expansion as the duration of the treatment was shorter than those in cases with mixed dentition and permanent dentition and also, methods of treatment were simpler, and the patients developed favourably.
\end{abstract}

Keywords: Unilat postcrossbite, primary dent,dento alveolar expansion.

\section{Introduction:}

Posterior crossbite is one of the most prevalent malocclusions in the primary and early mixed dentition and is reported to occur between $8 \%$ and $22 \%{ }^{1-4}$ In most cases, the crossbite is accompanied by a mandibular shift, a so-called forced crossbite, which causes midline deviation. ${ }^{2,5}$ Factors involved in the etiology of the crossbite, besides heredity, are sucking habits ${ }^{6}$ and impaired nasal breathing caused by, for example, enlarged tonsils and adenoids. ${ }^{7-9}$ The status of the primary occlusion affects the development of the permanent occlusion. Thus, a posterior crossbite is believed to be transferred from primary to permanent dentition, and the posterior crossbite can have long-term effects on the growth and development of the teeth and jaws. ${ }^{10,11}$ The abnormal movement of the lower jaw (mandibular shift) may place a special strain on the orofacial structures, causing adverse effects on the temporomandibular joints and masticatory system. EMG; electromyographic studies have shown that the activity of the temporal and masseter muscles is disturbed in children with unilateral crossbite. ${ }^{12,13}$

Background:Studies of adolescents and adults have revealed that patients with posterior crossbite have an increased risk to develop craniomandibular disorders, showing more signs and symptoms of these problems. ${ }^{414-16}$ Therefore, early treatment is often advised to normalize the occlusion and create conditions for normal occlusal development. ${ }^{1,10,17}$ Furthermore, postponement of treatment has been claimed to result in prolonged treatment of greater complexity. ${ }^{1,18}$

\section{Appliance design:}

Coffin springwas designed by Walter Coffin.It is a removable/fixed,omega shaped wire appliance which produces slow and bilaterally symmetrical expansion. It consists of omega shaped wire of $1.25 \mathrm{~mm}$ diameter placed in mid palatal region.Free ends of omega are embedded in an acrylic plate/ soldered onto the palatal surface of molar bands. It brings about dento alveolar expansion. However, it is capable of skeletal changes when used in mixed dentition with a good retention. ${ }^{19}$

Case report:A 5 year-old girl reported to the department with the chief complaint of pain and decayed teeth on lower right and left region of the jaw. Her medical history was noncontributory, intraoral examination revealed deep occlusal caries with 75 and 85 and maxillary arch no abnormality was detected (Figures 1 and 2).On further examination we could find unilateral posterior crossbite on left side, mesial step on right side and anterior openbite (figure 3,4 and 5). On parental history mother told that she has thumb sucking habit which was continuous and vigorous and she performed that even during sleeping hours. There were no interference and deviation of the mandible on closure. This patient showed oral breathing, lip incompetence, and atypical swallowing aided by the mentonian musculature. Pulptherapy was carried out with 75 and 85 and finally restored with stainless steel crowns considering the age of the child and the time the tooth will remain in the oral 
cavity. The treatment plan proposed for unilateral posterior cross bite was fixed coffin spring for the dentoalveolar expansion on the left side. Two bands were adapted onto the maxillary second primary molars and impression was made and poured with dental stone.coffin spring was fabricated $\mathrm{n}$ soldered to the palatal aspect of the bands and later appliance was removed from the cast and polished, cemented on the maxillary arch using glass ionomer cement(figure 6). The girl was also trained for the tongue exercises and taught remainder therapy for the thumb sucking habit, the girl was recalled after every week for the activation of the appliance. After 4 weeks of active treatment all her maxillary primary molars were into favorable occlusion and because of constant monitoring and motivation we could see the decrease in the anterior openbite(figure 7(a),7(b) and 8). The girl was advised to have a regular follow up.The girl was followed up for 8 months, and has as yet maintained stability of the results achieved with slow maxillary expansion (figure 8).

\section{Discussion:}

This case report challenges some studies ${ }^{5,18}$ in which this enlargement method of treatment was found to have a poor stability result. In the present case, the patient had unilateral dental posterior crossbite, and a fixed coffin spring appliance was indicated. Early correction of posterior crossbite has been recommended in order to prevent an inadequate skeletal transversal growth. As in the present case there was slow and steady dentoalveolar expansion, hence the chances of relapse was very less.

Several studies have been carried out during the last decade concerning early treatment of posterior crossbite, ie, treatment in the primary dentition or in the early mixed dentition usually before the age of nine years. However, a considerable variety in treatment approaches, study design, sample sizes, and research approach has produced disparate outcomes among these studies. Regarding intervention in the early mixed dentition, a high success rate was found and a substantial expansion effect was shown of treatment with QH, expansion plates, and RME. However, the remaining expansion, ie, expansion after retention and follow-up, was difficult to analyze and interpret because the follow-up time varied substantially among the studies. ${ }^{21}$

Studies have also shown that $50 \%$ of posterior crossbite cases treated at primary dentition had to be retreated at mixed dentition ${ }^{5,18}$. Although these results indicated a high-incidence relapse of early treatment, other advantages have been attributed to this intervention. According to Harrison and Ashby ${ }^{20}$, maxillary expansion in the primary dentition would decrease the risk of a posterior crossbite being perpetuated to a permanent dentition.

\section{Conclusion:}

The early and correct diagnosis of posterior crossbite is essential to prevent the forthcoming occlusal discrepancies in the permanent dentition. Adequate curative measures and treatment modalities should be advocated to correct the posterior crossbite.

\section{References:}

[1] Kutin, G. and R. R. Hawes. Posterior cross-bites in the deciduous and mixed dentitions. Am J Orthod1969. 56:491-504.

[2] Thilander, B. and N. Myrberg. The prevalence of malocclusion in Swedish schoolchildren. Scand J Dent Res 1973. 81:12-20.

[3] Heikenheimo, K. and K. Salmi . Need for orthodontic intervention in five-year-old Finnish children. Proc Finn Dent Soc 1987. 83:165-169.

[4] Egermark-Eriksson, I. , G. E. Carlsson, T. Magnusson, and B. Thilander . A longitudinal study on malocclusion in relation to signs and symptoms of cranio-mandibular disorders in children and adolescents. Eur J Orthod 1990. 12:399-407.

[5] Kurol, J. and L. Berglund . Longitudinal study and cost-benefit analysis of the effect of early treatment of posterior crossbites in the primary dentition. Eur J Orthod 1992. 14:173-179.

[6] Larsson, E. The effect of dummy-sucking on the occlusion: a review. Eur J Orthod 1986. 8:127-130.

[7] Linder-Aronson, S. Adenoids. Their effects on mode of breathing and nasal airflow and their relationships to characteristics of the facial skeleton and the dentition (thesis). ActaOtolaryngol. Suppl. 1970;265:1-132.

[8] Hannuksela, A. and A. Väänänen . Predisposing factors for malocclusion in 7-year-old children with special reference to atopic diseases. Am J OrthodDentofacialOrthop 1987. 92:299-303.

[9] Behlfelt, K. , S. Linder-Aronson, J. McWilliam, P. Neander, and J. Lange-Hellman . Dentition in children with enlarged tonsils compared to control children. Eur J Orthod 1989. 11:416-429.

[10] Proffit, W. R. Treatment of orthodontic problems in preadolescent children (section VI). In: Proffit WR, ed. Contemporary Orthodontics. 3rd ed. Mosby, St Louis; 2000:435-439.

[11] McNamara, J. A. Early intervention in the transverse dimension: is it worth the effort? Am J OrthodDentofacialOrthop 2002. 121:572-574.

[12] Troelstrup, B. and E. Möller. Electromyography of the temporalis and masseter muscles in children with unilateral cross-bite. Scand J Dent Res 1970. 8:425-430.

[13] Ingervall, B. and B. Thilander . Activity of temporal and masseter muscles in children with a lateral forced bite. Angle Orthod 1975. 45:249-258.

[14] Mohlin, B. and B. Thilander. The importance of the relationship between malocclusion and mandibular dysfunction and some clinical applications in adults. Eur J Orthod 1984. 6:192-204.

[15] Riolo, M. L., D. Brandt, and T. R. TenHave . Associations between occlusal characteristics and signs and symptoms of TMJ dysfunction in children and young adults. Am J OrthodDentofacialOrthop 1987. 92:467-477.

[16] Pullinger, A. G. , D. A. Seligman , and J. A. Gornbein . A multiple logistic regression analysis of the risk and relative odds of temporomandibular disorders as a function of common occlusal factors. J Dent Res 1993. 72:968-979.

[17] Clifford, F. O. Cross-bite correction in the deciduous dentition: principles and procedures. Am J Orthod1971. 59:343-349. 
[18] Lindner, A. Longitudinal study of the effect of early interceptive treatment in 4-year-old children with unilateral cross-bite. Scand J Dent Res 1989. 97:432-438.

[19] Pinkham, Casammassimo, McTigue, Nowak - Pediatric Dentistry Infancy Through Adolescence.

[20] Harrison JE, Ashby D. Orthodontic treatment for posterior crossbites. Cochrane Database Syst Rev. 2001;(1):CD000979.

[21] Bell RA, LeCompte EJ. The effects of maxillary expansion using a quad-helix appliance during the deciduous and mixed dentitions. Am J Orthod. 1981;79(2):152-61.

Legends for the figures:

1. Figure 1: mandibular arch showing deep occlusal caries with primary second molars.

2. Figure 2: maxillary arch showing intact dentition.

3. Figure 3: left lateral view showing unilateral posterior crossite.

4. Figure 4: right lateral view showing mesial step.

5. Figure 5: frontal view showing anterior openbite.

6. Figure 6: fixed coffin spring cemented onto the maxillary arch.

7. Figure 7(a): post treatment i.e after one month, left lateral view showing corrected crosbite. Figure 7(b): post treatment i.e after one month, right lateral view.

8. Figure 8: post treatment anterior view showing decreased anterior open bite.

Figures :

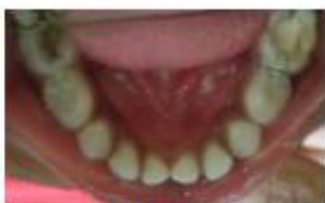

Figure 1

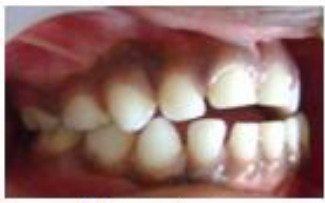

Figure 4

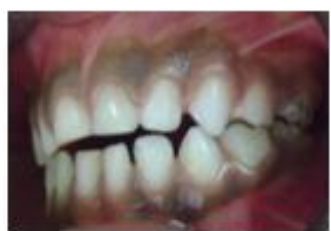

Figure 7(a)

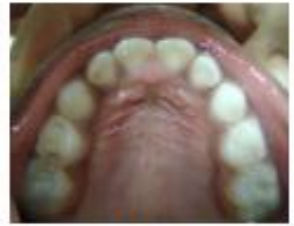

Figure 2

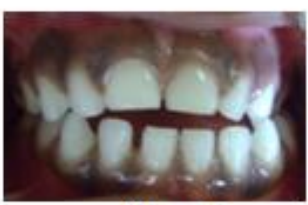

Figure 5

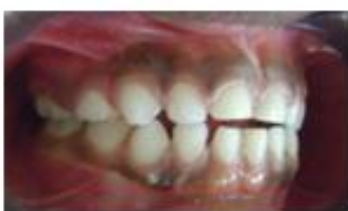

Figure 7(b)

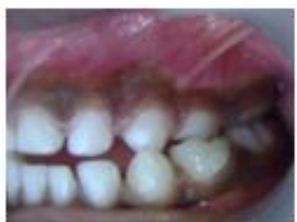

Figure 3

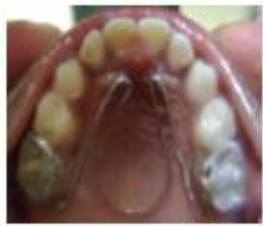

Figures 6

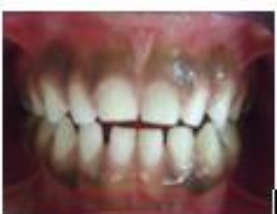

Figure 8 